\title{
The Determination of Sphenoid Sinus Dimensions in Turkish Healthy Adult Subjects: An MRI Study
}

\author{
Determinación de las Dimensiones del Seno Esfenoidal en Sujetos \\ Adultos Sanos Turcos: Un Estudio de Resonancia Magnética
}

\author{
Fatma Yasemin Öksüzler'; Sema Polat²; Mahmut Öksüzler³ Ayse Gül Uygur ${ }^{4}$ \& Ahmet Hilmi Yücel
}

\begin{abstract}
ÖKSÜZLER, F. Y.; POLAT, S.; ÖKSÜZLER, M.; UYGUR,A. G. \& YÜCEL, A. H. The determination of sphenoid sinus dimensions in Turkish healthy adult subjects: An MRI study. Int. J. Morphol., 37(1):22-27, 2019.

SUMMARY: The aim of this study was to identify sphenoid sinus dimensions; and distance between columella nasal and sphenoid sinus; and columella nasal and hypophysis in healthy adult subjects using magnetic resonance imaging (MRI) and to evaluate differences between genders and age groups. The MRI results of 300 healthy subjects (192 females; 108 males) aged 18-68 years were studied. The midsagittal and axial images were used for shape of the sphenoid sinus, and the distance measurements of its related adjacent structures on MRI. The mean values of the distance between columella nasal; and columella nasal and hypophysis; and sinus sphenoidalis width were $65.73 \pm 5.22 \mathrm{~mm}, 87.05 \pm 4.79 \mathrm{~mm}$ and $37.67 \pm 8.40 \mathrm{~mm}$ in females respectively, whereas the same values were $71.79 \pm 5.06 \mathrm{~mm}, 94.52 \pm 6.07 \mathrm{~mm}$ and $41.95 \pm 9.32 \mathrm{~mm}$ in males, respectively. The means of all measurements were lower in healthy female subjects than in healthy males.Additionally, the classification of sphenoid sinus types were determined to be postsellar type (131), sellar type (46), presellar type (14) and conchal type (1) in females, respectively. The same measurement were determined as postsellar type (82), sellar type (23) and presellar type (3) in males, respectively. Differences between sexes and age related changes were observed in the variations of the size, location and shape of sphenoid sinus were observed The observations presented in this report have defined anatomic parameters that need to be taken into consideration for reference data to determine gender discrepancies, age related changes and helpful for radiologists and clinicians to plan safe surgical approach and avoid surgical risks.
\end{abstract}

KEY WORDS: Sphenoid bone; Sphenoid sinus; Magnetic resonance imaging.

\section{INTRODUCTION}

Sphenoid bone is more important structure of skull base surgery. Sphenoid sinus is the most remained hidden and unreachable of the paranasal sinuses (Mamatha et al., 2014; Sevinc et al., 2014; Wiebracth \& Zimmer, 2014). This allows to safely approach the sella turcica, optic nerve, tuberculum sella and planum sphenoidale for surgeons, in some lesions including skull base lesions and cerebrospinal fluid leaks (Wiebracth \& Zimmer). Sphenoid sinus continues to develop during puberty and reaches adult size by 12 age (Wiebracth \& Zimmer). It is bordered at the many serious structures like cavernous sinus laterally, the eithmoidal air cells, anterior cranial fossa and optic nerve anteriorly, the clivus posteriorly, the hypophysis fossa and planum sphenoidale superiorly, choana inferiorly, internal carotid artery medially (Mamatha et al.; Seddinghi et al., 2014; Sevinc et al.; Farımaz et al., 2018). Sphenoid sinus shows difference in size, shape and degree of pneumatization (Yamashita et al., 2014). Variations in septation, shape, and dimensions have a serious effect on surgical planning of the skull base (Wiebracth \& Zimmer). The sphenoid sinus variations were classified into four types as conchal, presellar, postsellar and sellar (Yamashita et al.). A detailed knowledge of the anatomy of sphenoid sinus and its related adjacent structures preoperatively is vital to the prevention of unintentional damage to these significant structures during surgery implementation (Fasunla et al., 2012). Because, any injury to the lateral, posterior or superior of the sphenoid sinus can induce cerebrospinal fluid leaks and this endangers to surrounding regions like optic canal, vidian canal, maxillary, oculomotor, trochlear and abducens nerves, the cavernous sinuses (Wiebracth \& Zimmer). The hypophysis which is composed of two anatomically and functionally

\footnotetext{
${ }^{1}$ Adana City Hospital, Department of Radiology, Adana, Turkey.

${ }^{2}$ Cukurova University, Faculty of Medicine, Department of Anatomy. Balcal1-Sarıçam/Adana, Turkey.

${ }^{3}$ Adana Medline Hospital, Department of Radiology, Adana, Turkey.

${ }^{4}$ Cukurova University, Faculty of Medicine, Department of Anatomy. Balcalı-Sarıçam/Adana, Turkey.
} 
distinct lobes (the anterior and the posterior lobe), are located beneath the brain in the center of the skull base. It is responsible for connecting two major homeostatic systems of the body the nervous and endocrine systems. The MRI of hypothalamichypophysis region which is used as diagnostic method, may provide more details of the structures that constitutes the central nervous system and the skull base (Yamashita et al.). In the removal of hypophysis tumors, some methods are used that the endoscopic and microscopic transsphenoidal approaches have accepted as a more safe procedure according to transcranial approach (Kim et al., 2013).

The purpose of this study was to document the shape of sphenoid sinus and the distance measurements between adjacent structures and sphenoid sinus, sphenoid sinus anatomic parameters and to plan safe surgical approach and avoid surgical risks for radiologists and clinicians using MRI in healthy females and males in our population and to identify the sex and age related differences.

\section{MATERIAL AND METHOD}

This study was carried out from the 300 healthy adult subjects (192 females; 108 males) aged 18-68 years (35.62 \pm 10.65 years) over a period of 4 years between January 2014 and 2018. All the test procedures were approved by ethics committee. Cranial MRI findings were evaluated by radiologists and anatomists. Healthy adult subjects were selected by criteria of optimal health. Moreover, inclusion criteria for healthy adult subjects were no history of

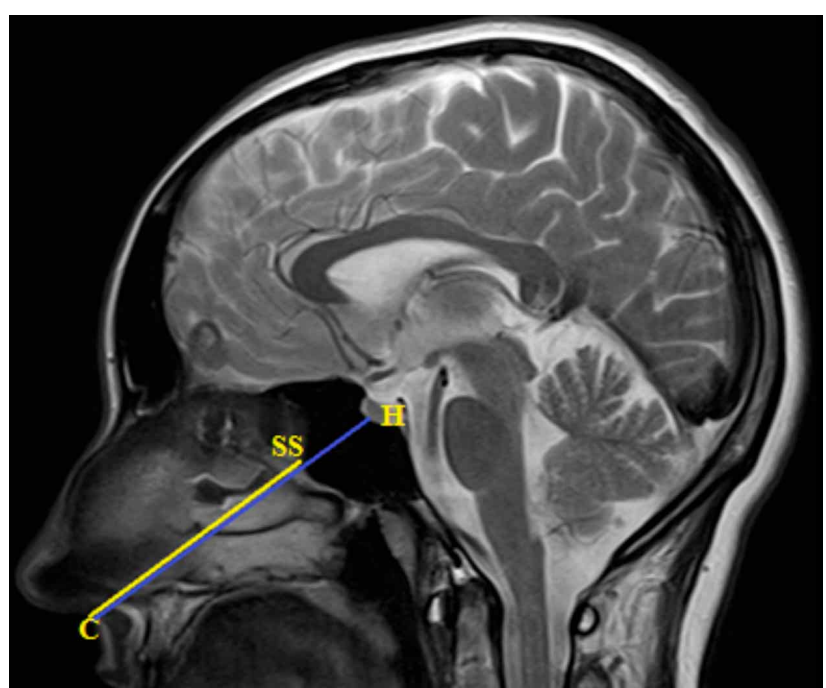

Fig. 1. Midsagittal T2-weighted Spin Echo MRI (TR:3600, TE:87 $\mathrm{ms}$ ) of measurement areas of female and male healthy subjects. (CSS) The distance between columella nasal and sphenoid sinus. The distance between columella nasal and hypophysis $(\mathrm{CH})$. oncologic illness, hemiplegia, intracranial lesions, Parkinson disease, having surgical operation related region, psychiatric or medical illness and surgery of the sphenoid sinus, sinonasal tumor or nasal polyposis and chronic rhinosinusitis. MRI was performed using a 1.5 T MRI system (Siemens; Essenza, Erlangen, Germany). Brain MRI protocol including axial T2-weighted turbo spin echo (TR:3600, TE:87 ms; slice thickness $5 \mathrm{~mm}$; gap $1.5 \mathrm{~mm}$ ) and sagittal T2-weighted spin echo (TR:3600, TE: $87 \mathrm{~ms}$; slice thickness $5 \mathrm{~mm}$; gap 1.5 $\mathrm{mm}$ ) was used. The measurements were performed from digital MRI images on a hospital using caliper function with $\mathrm{x} 2$ magnification. Using the midsagittal T2-weighted spin echo image, the following parameters of sphenoid sinus dimensions were evaluated (Baskin et al., 2003; Güldner et al., 2012; Kim et al.; Hindi et al., 2014; Sevinc et al.; Lupascu et al., 2014; Rahmati et al., 2016; Souadih et al., 2018) (Fig. 1).

(CSS) The distance between the columella nasal and sphenoid sinus.

(CH) The distance between the columella and hypophysis (pituitary gland).

(SSW) The width of sphenoid sinus

(SST) The sphenoid sinus types (It is expressed as conchal type, when the sinus is separated from the sella by thick trabecular bone; it is stated as presellar type, when the sinus is pneumatised without extending posteriorly of the sellar floor and sellar type is when the sinus extends inferiorly and posteriorly of the sella turcica. It words as postsellar type if posterior wall of sphenoid sinus is behind the posterior wall of the sella turcica).

The data were divided into two groups: healthy adult female and male subjects. Estimations were expressed as millimeters. The SPSS 21.0 program was used for statistical analysis of the measurement results. From these measurements, means, standard deviations (SD), minimum and maximum values were calculated; In all statistical analyses; a p value under 0.05 was considered statistically significant.

\section{RESULTS}

The means of age of 192 healthy females and 108 healthy males were $35.24 \pm 11.07$ years and $36.31 \pm 9.86$ years, respectively. MRI results of the parameters of sphenoid sinus sub-regions $(\mathrm{mm})$ in healthy adult subjects were shown in Table I. From the 300 MRI images, various dimensions of sphenoid sinus were measured (Fig. 1).

The mean scores of the distance between columella nasal and sphenoid sinus (CSS), the distance between 
columella nasal and hypophysis $(\mathrm{CH})$ and the width of sphenoid sinus (SSW) were higher in healthy male subjects than in females subjects. The pneumatization degree were determined as postsellar type (131), sellar type (46), presellar type (14) and conchal type (1) were in healthy female subjects, whereas the same parameter were postsellar type (82), sellar type (23) and presellar type (3) in healthy male subjects. Moreover, the means of distance between columella nasal and sphenoid sinus, columella nasal and hypophysis and sinus sphenoidalis width were
$65.73 \pm 5.22 \mathrm{~mm}, 87.05 \pm 4.79 \mathrm{~mm}$ and $37.67 \pm 8.40 \mathrm{~mm}$ in females respectively, whereas the same values were $71.79 \pm 5.06 \mathrm{~mm}, 94.52 \pm 6.07 \mathrm{~mm}$ and $41.95 \pm 9.32 \mathrm{~mm}$ in males, respectively. According to these results, there were statistically significantly differences in all parameters excluding the sphenoid sinus types in between two groups (Tables I and II). Furthermore, when we investigated age related changes of groups there were significant difference in all parameters except sphenoid sinus width and differenceswere between group I and group III.

Table I. MRI measurements related with sphenoid sinus $(\mathrm{mm})$ in healthy adult subjects.

\begin{tabular}{|c|c|c|c|}
\hline \multicolumn{2}{|l|}{ Groups } & \multicolumn{2}{|c|}{ Healthy group:300 } \\
\hline \multicolumn{2}{|l|}{ Measurements } & \multicolumn{2}{|c|}{ Mean \pm Standard deviation } \\
\hline \multicolumn{2}{|l|}{ Sex } & F emales $(n=192)$ & Males $(n=108)$ \\
\hline \multicolumn{2}{|l|}{ Age (years) } & $35.24 \pm 11.07$ & $36.31 \pm 9.86$ \\
\hline \multicolumn{2}{|c|}{ Significance of sexes in the same group (p) } & \multicolumn{2}{|c|}{$>0.05$} \\
\hline \multicolumn{2}{|c|}{ Sinus sphenoidalis width (CCL) } & $37.67 \pm 8.40$ & $41.95 \pm 9.32$ \\
\hline & \multicolumn{2}{|c|}{$<0.05$} \\
\hline & pophisis $(\mathrm{CH})$ & \multicolumn{2}{|r|}{$94.52 \pm 6.07$} \\
\hline \multicolumn{2}{|c|}{$\begin{array}{l}\text { The distance between columella nasal and hypophisis (CH) } \\
\text { Significance of sexes in the same group (p) }\end{array}$} & \multicolumn{2}{|c|}{$<0.05$} \\
\hline \multicolumn{2}{|c|}{ The distance between columella nasal and sphenoid sinus (CSS) } & $65.73 \pm 5.22$ & $71.79 \pm 5.06$ \\
\hline Significance of sex es in the & & \multicolumn{2}{|c|}{$<0.05$} \\
\hline \multirow[t]{4}{*}{ Sphenoid sinus types (SST) } & Postsellar type & $131(68 \%)$ & $82(76 \%)$ \\
\hline & Sellar type & $46(24 \%)$ & $23(21 \%)$ \\
\hline & Presellar type & $14(7 \%)$ & $3(3 \%)$ \\
\hline & Conchal type & $1(1 \%)$ & - \\
\hline \multicolumn{2}{|c|}{ Significance of sexes in the same group (p) } & \multicolumn{2}{|c|}{$>0.05$} \\
\hline
\end{tabular}

Table II. Age related changes of sphenoid sinus measurements in healthy adult subjects

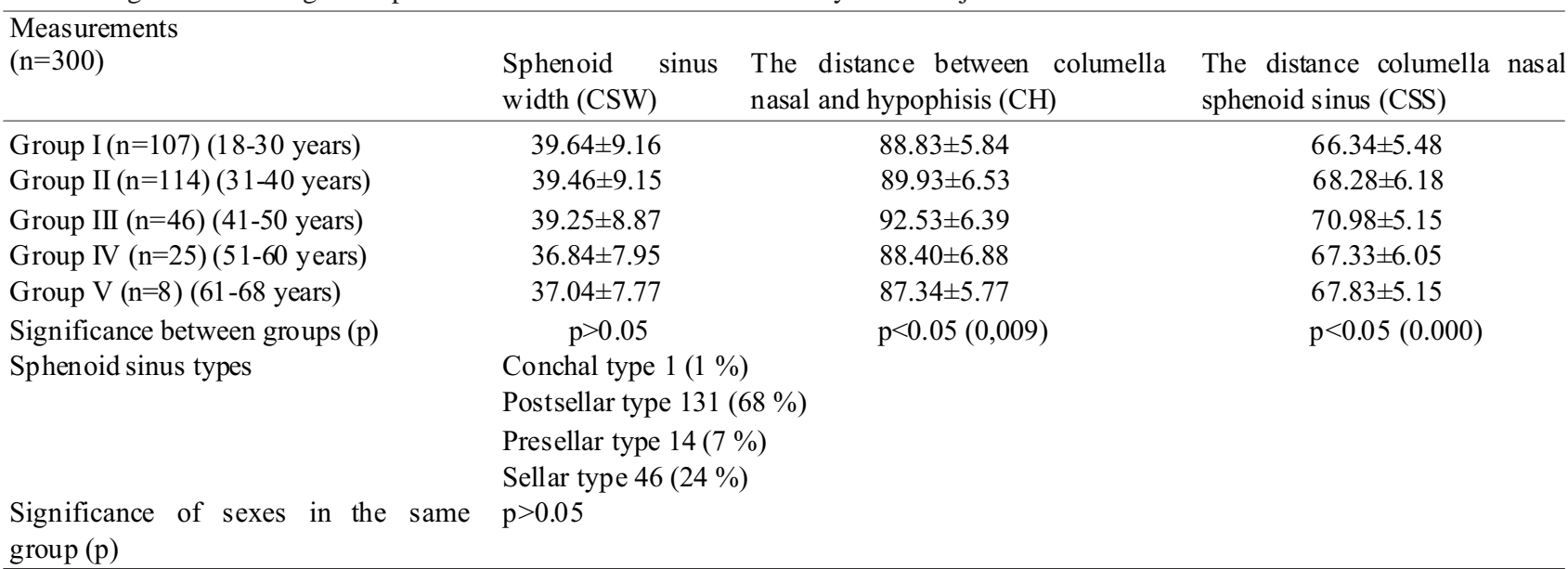

\section{DISCUSSION}

In this study, we measured several parameters about sphenoid sinus, the sphenoid sinus types (the degree of pneumatization), the relation with sphenoid sinus and hypophysis of columella nasal in both healthy female and male subjects and compared our findings to both sexes and other populations. In fact, there are several surgery methods 
and surgical landmark. So, these type studies including different populations are significant in terms of showing the discrepancies in both female and male subjects at the same age with using MRI.

The crucial subject for the decision of surgery of sellar region was the size and degree of pneumatization of sphenoid sinus or sphenoid sinus types (Seddinghi et al., 2014). The degree of pneumatization or sphenoid sinus types and its relation to sella turcica was best evaluated on the sagittal scans of MRI (Hamid et al., 2008; Sevinc et al.; Seddinghi et al., 2014). The detailed preoperative imaging of sphenoid sinus and sellar region by MRI was needed for suitable surgical approach and prevention of risks (Seddinghi et al., 2014). Moreover, MRI can give information about significant soft tissue patterns, including the ca-rotid artery, sella turcica, sella floor, and the sphenoid sinus wall. Furthermore, MRI can provide certain evaluations in surgery of hypophysis adenomas as a preoperative evaluation such as CT (Kim et al.). In the techniques of neuroimaging, MRI is used as diagnostic method for the field of hypothalamichypophysis region. It may examine in detail of the structures that constitute the central nervous system (CNS), sellar and perisellar regions and skull base. Additionally, it has a high sensitivity to specify subtle changes (Yamashita et al.).

The most changeable paranasal sinuses is sphenoid sinus in terms of many factors including degree and type of pneumatization and relation with surrounding surgical risks (i.e. optic, occulomotor, trochlear, trigeminal or abducens nerves, internal carotid artery or hypophysis). There are many variations in sphenoid sinus anatomy (Lupascu et al.). Having a detailed knowledge of the relations and variable regional anatomy of the sphenoid sinus before operation may guide surgeon in surgical success and decreases surgical complications and fatal risks (Seddinghi et al., 2014; Lupascu et al.; Rahmati et al.). The sphenoid sinus is the most important and variable structure of the paranasal surgery which makes it difficult to approach. Safe access to the sellar region is quite influenced by the pattern of pneumatization in the sphenoid sinus. Anatomic variations are predispose the sphenoid sinus to recurrent or chronic sinusitis (Rahmati et al.). The types of the sphenoid sinus can be defined in four groups: I. conchal, II. presellar, III. sellar and IV. postsellar. This classification is done depending on the extent to which the sphenoid bone is pneumatized (Kim et al.; Sevinc et al.; Lupascu et al.). In the conchal type which makes dificulties to surgery, the region below the sella is a solid block of bonewithout an air cavity. In the presellar type which has no bulge of the sellar floor in the sphenoid sinus. This situation provides disadvantageous to transsphenoidal surgery. Moreover, the sphenoid sinus has reasonable air cavity with no sellar recess and its posterior wall is in the front of the anterior wall of the sella turcica. In the sellar type, which is the most common and ideal anatomic shape, when the sella turcica is approached from below, since the floor bulges into direct view of the operative field. In the postsellar type which has roomy sinuses, intercarotid distance and thin anterior wall and floor of sella turcica, provides suitable conditions for transsphenoid hypophysectomy and sphenoid sinus posterior wall is behind the sella turcica posterior wall. However a bony block hinders the range of the vision of the sella turcica (Baskin et al.; Kayalioglu et al., 2005; Güldner et al.; Kim et al.; Hindi et al.; Sevinc et al.; Lupascu et al.; Rahmati et al.; Souadih et al.).

The incidence of the sellar type sphenoid sinus in literature was reported as 53-89\%, whereas the presellar type was declared as 10-38\%. Moreover, conchal type was found between $0 \%$ and $9 \%$ (Hamid et al.; Lupascu et al.). When we analysed our data including sphenoid sinus types, the postsellar type (68-76\%) pneumatization was the most seen, whereas the least seen type was the conchal type (1-0 $\%)$ in females and males, respectively. The most common type of the sphenoid sinus was the postsellar type $(49.4 \%)$, followed by sellar type (44.4\%) and presellar type (5.6\%), and the least encountered was the conchal type $(0.6 \%)$ were seen in Korean population (Kim et al.). The most seen of the sphenoid type was the sellar type (78.9\%), followed by postsellar type $(15.3 \%)$, and presellar type $(5.8 \%)$ in Brazilians (Yamashita et al.). In Iran, the most prevelant type was the postsellar type (83.5\%), followed by sellar type $(14.6 \%)$ and the least encountered was the presellar type $(1.9 \%)$. Conchal type was not seen in Iranians. Also, the postsellar type was represented mostly in males than females (Rahmati et al.). Furthermore, it was reported that the least frequent type in literature was conchal type (Baskin et al.; Kayalioglu et al.; Sareen et al., 2005; Hamid et al.; Kim et al.; Hindi et al.; Mamatha et al.; Sevinc et al.; Vidya \& Raichurkar, 2015; Rahmati et al.). Kayalioglu et al., reported that conchal type, presellar type, sellar type and postsellar type were seen at rate of $4.2 \%, 8.3 \%, 60.4 \%$ and $27.1 \%$, respectively. Also, the same measurements were at rate of 0 $\%, 13.8 \%, 69 \%$ and $17.2 \%$ in cadavers, respectively. In MRI, the same dimensions were $1.7 \%, 8.3 \%, 48.3 \%$ and $41.7 \%$, respectively. Additionally, conchal type sphenoid sinus was more prevalent in females than males, but presellar type sphenoid sinus was more in males than females (Kayalioglu et al.). In Egypt, there were $2 \%$ conchal type, and $21 \%$ presellar type, and $54.7 \%$ sellar type and $22.3 \%$ postsellar type (Hamid et al.). It was stated that sellar type sphenoid sinus (55-85\%), and presellar type sphenoid sinus (25-10\%), and postsellar type sphenoid sinus (20-5\%) was found in Indians (Mamatha et al.; Vidya \& Raichurkar). In ethnic group including Malay, Chinese and Indian 
population, postsellar type sphenoid sinus was reported as $83.3 \%$ whereas, presellar type sphenoid sinus was declared as $16.7 \%$. There was no conchal type sphenoid sinus in same populations. However, there was no statistical relationship between races and sphenoid types (Hindi et al.). Due to these data in males we found some differences in the prevelance of the sphenoid sinus types of Brazilians, Egypt, Indian populations and Turkish population with our healthy female and male population (Kayalioglu et al.; Hamid et al.; Budu et al., 2013; Mamatha et al.; Yamashita et al.; Vidya $\&$ Raichurkar). Our result of the least sphenoid sinus type which was conchal type was in concordance with literature (Kayalioglu et al.; Sareen et al.; Hamid et al.; Mamatha et al.; Hindi et al.; Vidya \& Raichurkar).

In Brazilian males the sphenoid sinus was larger than females and it increased with increasing age (Yamashita $e t$ $a l$.). However, the mean values of the sphenoid sinus width of females were $24.5 \mathrm{~mm}$. In males the same dimension were $27 \mathrm{~mm}$ (Yamashita et al.). In Japanese male and female population there was no significant difference in the sphenoid sinus width (Yonetsu et al., 2000). While our result (37.67 $\pm 8.40 \mathrm{~mm}$ in females; $41.95 \pm 9.32 \mathrm{~mm}$ in males) was similar to Brazilians, it was different from Japanese population. However, in our population sphenoid sinus width decreased with increasing age until 60 years.

The mean values of distances from the base of the columella nasal to the anterior wall of the sphenoid sinus and the sellar floor were $69.71 \pm 4.25 \mathrm{~mm}$ and $86.26 \pm 4.57$ $\mathrm{mm}$, respectively in Korean population (Kim et al.). In Brazilian female subjects, the means of the distances from the base of the columella nasal to the anterior wall of the sphenoid sinus and the distance from hypophysis to columella nasal were as $66 \mathrm{~mm}-83.5 \mathrm{~mm}$. The corresponding values of Brazilian males were as $77.0 \mathrm{~mm}$ $89.0 \mathrm{~mm}$ respectively (Yamashita et al.). The means of the distances from the base of the columella nasal to the anterior wall of the sphenoid sinus and the distance from hypophysis to columella nasal of Turkish females were $66.2 \pm 5.2 \mathrm{~mm}$ and $80.2 \pm 5.5 \mathrm{~mm}$ respectively, whereas the same dimensions were $71.2 \pm 5.7 \mathrm{~mm}$ and $85.6 \pm 5.8 \mathrm{~mm}$ in males, respectively (Kayalioglu et al.). In our study, the same measurements were $65.73 \pm 5.22 \mathrm{~mm}$ and $71.79 \pm 5.06 \mathrm{~mm}$; $87.05 \pm 4.79 \mathrm{~mm}$ and $94.52 \pm 6.07 \mathrm{~mm}$ in females and males, respectively. Due to these data in males we found some differences in the mean values of distance between columella nasal to the sphenoid sinus of Koreans and Brazilians with our healthy males. The Korean and Turkish population having lower, and Brazilians having greater values than ours. Similarly, when we analyzed our data in female population we observed that there are differences Korean and Turkish population and our population data. But, our result is simi- lar to Brazilian female subjects. Moreover, when comparing the means of the distance from columella nasal to hypophysis with this paper of female and male population scores of Korean, Turkish and Brazilian female and male population were lower than our this data. Also, we think that these discrepancies may originate from race, age, genetic, enviromental condition and sex, some diseases. When we investigated age-related changes for $\mathrm{CSS}$ and $\mathrm{CH}$, there was significant difference between Group 1 and Group III $(\mathrm{p}<0.05)$. Moreover, sphenoid sinus width decreased with increasing age (between 18 and 60 years). Conversely, in between 18 and 50 years, the distance between columella nasal and sphenoid sinus and hypophysis increased. But after 51 years the same measurements decreased again.

As a conclusion, the data indicated that sphenoid sinus has significant variations and shows frequently differences from race to race. The observations presented in this study have defined anatomic parameters that need to be taken into consideration to evaluate sphenoid sinus variations and problems and guidelines to determine the reference values in terms of sexes and age. Also, this paper can provide crucial information and may be essential for safe and accurate diagnosis of many anatomical variations.

Having a detailed knowledge of the anatomical structures in sphenoid sinus and sellar region will help to evaluate both normal and pathological changes for surgeon, radiologist or neuroscientist about assessment of pathologic changes in the sphenoid sinus and sellar region region using with MRI.

ÖKSÜZLER, F. Y.; POLAT, S.; ÖKSÜZLER, M.; UYGUR, A. G. \& YÜCEL, A. H. Determinación de las dimensiones del seno esfenoidal en sujetos adultos sanos turcos: un estudio de resonancia magnética. Int. J. Morphol., 37(1):22-27, 2019.

RESUMEN: El objetivo de este estudio fue identificar las dimensiones del seno esfenoidal y la distancia entre la columela nasal y el seno esfenoidal y, la glándula nasal y la hipófisis en sujetos adultos sanos con imágenes de resonancia magnética (RM), para evaluar las diferencias entre los sexos y los grupos de edad. Se estudiaron los resultados de RM de 300 sujetos sanos (192 mujeres, 108 hombres) de 18 a 68 años. Se usaron imágenes sagitales y axiales para la forma del seno esfenoidal y las mediciones de distancia de sus estructuras adyacentes relacionadas en la RM. Los valores medios de la distancia entre columela nasal; y columela nasal e hipófisis; y la anchura del seno esfenoidal fue de $65,73 \pm 5,22 \mathrm{~mm}, 87,05 \pm$ $4,79 \mathrm{~mm}$ y $37,67 \pm 8,40 \mathrm{~mm}$ en mujeres, respectivamente, mientras que los mismos valores fueron de 71,79 $\pm 5,06 \mathrm{~mm}, 94,52 \pm 6,07$ $\mathrm{mm}$ y 41,95 $\pm 9,32 \mathrm{~mm}$ en varones, respectivamente. Las medias de todas las mediciones fueron menores en mujeres sanas que en hombres sanos. Adicionalmente, se determinó que la clasificación del seno esfenoidal era de tipo postsellar (131), tipo selar (46), tipo 
presellar (14) y tipo conchal (1), en las mujeres, respectivamente. Las mismas medidas se determinaron como tipo postsellar (82), tipo sellar (23) y tipo presellar (3) en varones, respectivamente. Se observaron diferencias entre sexos y los cambios relacionados con la edad en las variaciones de tamaño, ubicación y forma del seno esfenoidal. Las observaciones presentadas en este informe establecen parámetros anatómicos que se deben considerar como referencia para determinar las diferencias de sexo, y edad. La información de estas diferencias será útil para los radiólogos y los médicos en la planificación de un abordaje quirúrgico seguro y para evitar riesgos quirúrgicos.

\section{PALABRAS CLAVE: Hueso esfenoides; Seno esfenoidal;}

\section{Resonancia magnética.}

\section{REFERENCES}

Baskin, J. Z.; Kuriakose, M. A. \& Lebowitz, R. A. The anatomy and physiology of the sphenoid sinus. Oper. Tech. Otolaryngol. Head Neck Surg., 14(3):168-72, 2003.

Budu, V.; Mogoanta, C. A.; Fanuta, B. \& Bulescu, I. The anatomical relations of the sphenoid sinus and their implications in sphenoid endoscopic surgery. Rom. J. Morphol. Embryol., 54(1):13-6, 2013.

Farımaz, M.; Çelik, H. H.; Ergun, K. M.; Akgöz, A. \& Urfalı, B. The morphometry of the cavernous part of the internal carotid artery. Folia Morphol. (Warsz), 2018. doi: 10.5603/FM.a2018.0045. Epub ahead of print.

Fasunla, A. J.; Ameye, A. S.; Adebola, O. S.; Ogbole, G.; Adeleye A. O. \& Adekanmi, A. J. Anatomical variations of the sphenoid sinus and nearby neurovascular structures seen on computed tomography of black africans. East Cent. Afr. J. Surg., 17(1):57-64, 2012.

Güldner, C.; Pistorius, S. M.; Diogo, I.; Bien, S.; Sesterhenn, A. \& Werner, J. A. Analysis of pneumatization and neurovascular structures of the sphenoid sinus using cone-beam tomography (CBT). Acta Radiol., 53(2):214-9, 2012.

Hamid, O.; El Fiky, L.; Hassan, O.; Kotb, A. \& El Fiky S. Anatomic variations of the sphenoid sinus and their impact on trans-sphenoid pituitary surgery. Skull Base, 18(1):9-15, 2008.

Hindi, K.; Alazzawi, S.; Raman, R.; Prepageran, N. \& Rahmat, K. Pneumatization of mastoid air cells, temporal bone, ethmoid and sphenoid sinuses. Any correlation? Indian J. Otolaryngol. Head Neck Surg., 66(4):429-36, 2014

Kayalioglu, G.; Erturk, M. \& Varol, T. Variations in sphenoid sinus anatomy with special emphasis on pneumatization and endoscopic anatomic distances. Neurosciences (Riyadh), 10(1):79-84, 2005.

Kim, Y. H.; Kim, J. E.; Kim, M. J. \& Cho, J. H. New landmark for the endoscopic endonasal transsphenoidal approach of pituitary surgery. $J$. Korean Neurosurg. Soc., 53(4):218-22, 2013.

Lupascu, M.; Comsa, Gh. I. \& Zainea, V. Anatomical variations of the sphenoid sinus - a study of 200 cases. ARS Med. Tomitana, 2(77):57-62, 2014.

Mamatha, H.; Saraswathi, G. \& Prasanna, L. C. Variations of sphenoid sinus and their impact on related neurovascular structures. Curr. Neurobiol., l(2):121-4, 2010.

Rahmati, A.; Ghafari, R.\& AnjomShoa, M. Normal variations of sphenoid sinus and the adjacent structures detected in cone beam computed tomography. J. Dent. (Shiraz), 17(1):32-7, 2016.

Sareen, D.; Agarwal, A. K.; Kaul, J. M. \& Sethi, A. Study of sphenoid sinus anatomy in relation to endoscopic surgery. Int. J. Morphol., 23(3):261-6, 2005.

Sevinc, O.; Is, M.; Barut, C. \& Erdogan, A. Anatomic variations of sphenoid sinus pneumatization in a sample of Turkish population: MRI study. Int. J. Morphol., 32(4):1140-3, 2014.
Souadih, K.; Belaid, A. \& Salem, D. B. Fully automatic segmantation of sphenoid sinus in CT images with 3D convolutional neural networks. Amsterdam, $1^{\text {st }}$ Conference on Medical Imaging with Deep Learning (MIDL 2018), 2018.

Vidya, C. S. \& Raichurkar, K. Anatomic variation of sphenoid sinus in mysore based population: CT scan study. Int. J. Anat. Res., 3(4):16114, 2015.

Wiebracth, N. D. \& Zimmer, L. A. Complex anatomy of the sphenoid sinus: a radiographic study and literature review. J. Neurol. Surg. B Skull Base, 75(6):378-82, 2014.

Yamashita, S.; Resende, L. A.; Trindade, A. P. \& Zanini, M. A. A radiologic morphometric study of sellar, infrassellar and parasellar regions by magnetic resonance in adults. Springerplus, 3:291, 2014.

Yonetsu, K.; Watanabe, M. \& Nakamura, T. Age-related expansion and reduction in aeration of the sphenoid sinus: volume assessment by helical CT scanning. A. J. N. R. Am. J. Neuroradiol., 21(1):179-82, 2000 .

\section{Corresponding author: \\ Dr. Sema Polat \\ Çukurova University \\ Faculty of Medicine \\ Department of Anatomy \\ 01330 Adana \\ TURKEY}

\section{E-mail: sezaoz@hotmail.com}

Received: 24-07-2018

Accepted: 30-09-2018 